\title{
Using Hydraulic Engineering Model Experiment to Study the Sediment Trapping Efficiency of Adjustable Check Dam
}

\author{
Shu-Tzu Chen', Hung-Ming Shu', Shin-En Chiu², Chung-Li Hsu² ${ }^{2}$ \\ ${ }^{1}$ Department of Civil Engineering, National Pingtung University of Science and Tehnology, Taiwan \\ ${ }^{2}$ Department of Soil and Water Conservation, National Pingtung University of Science and Tehnology, Taiwan \\ Email: ${ }^{\text {c }}$ lhsu@mail.npust.edu.tw
}

Received 28 August 2015; accepted 25 July 2016; published 28 July 2016

Copyright (C) 2016 by authors and Scientific Research Publishing Inc.

This work is licensed under the Creative Commons Attribution International License (CC BY). http://creativecommons.org/licenses/by/4.0/

\section{(c) (i) Open Access}

\section{Abstract}

The construction of fully closed check dam (CD) is a conventional flood prevention mechanism implemented on rivers. Fully closed CDs trap large amounts of sediments in rivers to stabilize the river slopes and control erosion. However, fully closed CDs cannot selectively trap sediment and may easily overflow, causing them to losing their ability to mediate and hold sediments. Previous studies proposed the concept of "breathable CDs". The researcher introduced metal slit dam (SD) that could be assembled and disassembled quickly and conveniently. Once a CD reaches maximum capacity, operators must ensure that the water channels of the dam are free from blockage. Moreover, they must inspect the internal accumulation conditions of the dam periodically or immediately following heavy typhoon rains. When necessary, either the sediment buildup in the upriver blockage must be cleared, or the transverse structure of the dam must be removed to allow fine particles to be discharged along with a moderate amount of water. These actions can free up the sediment-storing capacity of the dam for the next heavy typhoon rains. In addition, operators should also inspect the damages inflicted on the dam, such as erosion, wear and tear, and deformation conditions. Damaged components should be disassembled and repaired if possible, or recycled and reused. The present study performed channel tests to simulate closed CDs, SDs, steel pipe dam (SPDs), and steel pipe plus slit dam (SPSDs) for 50-year and 100-year frequency floods. Results were then analyzed to determine the sediment trapping (ST) effects of various CDs, the effects of "adjustable CDs", and the changes of moderated riverbeds.

${ }^{*}$ Corresponding author.

How to cite this paper: Chen, S.-T., Shu, H.-M., Chiu, S.-E. and Hsu, C.-L. (2016) Using Hydraulic Engineering Model Experiment to Study the Sediment Trapping Efficiency of Adjustable Check Dam. Engineering, 8, 471-480.

http://dx.doi.org/10.4236/eng.2016.87044 
Keywords

Sediment Trapping, Check Dam, Riverbed Change, Hydraulic Engineering Model Experiment

\section{Introduction}

Taiwan is located at the boundary between the Eurasian Plate and the Philippine Sea Plate. The tectonic movement and compression of these plates over millions of years formed the steep and fragile landscape of Taiwan. During the rainy season, excessive rainfall often causes flooding and landslides in many areas of Taiwan. Thus, flood prevention mechanisms must be established in at river locations to reduce the threat of river sediments.

The construction of fully closed check dam (CD) is a conventional flood prevention mechanism implemented on rivers. Fully closed CDs trap large amounts of sediments in rivers to stabilize the river slopes and control erosion [1]-[3]. However, fully closed CDs cannot selectively trap sentiment and may easily overflow, causing them to losing their ability to mediate and hold sediments. Since the after math of Typhoon Morakot, the CDs on Chihpen River have maintained full capacity, gradually elevating the riverbed. If the riverbed continues to elevate each year, the flood area of the river would continue to expand downriver, where numerous densely populated settlements and tourist locations are located, causing irreparable damage to people, farmlands, and private buildings.

Chen et al. [4] and Chen \& Wu [5] proposed the concept of "Breathable CDs". The researcher introduced metal slit dam (SD) that could be assembled and disassembled quickly and conveniently. Once a CD reaches maximum capacity, operators must ensure that the water channels of the dam are free from blockage. Moreover, they must inspect the internal accumulation conditions of the dam periodically or immediately following heavy typhoon rains. When necessary, either the sediment buildup in the upriver blockage must be cleared, or the transverse structure of the dam must be removed to allow fine particles to be discharged along with a moderate amount of water [6]-[11]. These actions can free up the sediment-storing capacity of the dam for the next heavy typhoon rains. In addition, operators should also inspect the damages inflicted on the dam, such as erosion, wear and tear, and deformation conditions. Damaged components should be disassembled and repaired if possible, or recycled and reused. CDs should be conceptualized as "sediment traps". "Breathable CD" concepts should also be incorporated to moderate the height of CDs, thereby resolving extant river sedimentation problems.

The present study performed channel tests to simulate closed CDs, SDs, steel pipe dam (SPDs), and steel pipe plus slit dam (SPSDs) 50-year 100-year floods. Results were then analyzed to determine the sediment trapping (ST) effects of various CDs, the effects of "adjustable CDs", and the changes of moderated riverbeds [12]-[15].

\section{Materials and Methods}

\subsection{Study Area Introduction}

The Chihpen River Catchment was selected as the research area, whichis located in the southeastern region of Taiwan (Figure 1). The west side of the river basin starts from the Central Mountain Range and stretches eastwards to the Pacific Ocean. The south region of the water basin is separated by Guina Mountain, Taimali Mountain, and Xichuan Mountain from the Taimali River basin. At the north border of the Chihpen River basin are the Kedala Mountain, Zhuifen Mountain, and Shemagan Mountain at, which mark the boundary to the Lijia River Watershed. The river extends from northeastern ridgeline to the southwest and the elevation of watershed is between 1000 to $2000 \mathrm{~m}$. The gradient of the flow area is larger upriver, and gradually relaxes towards the mid-river and downriver areas. The development of the land and river terrains in the area is in the early to mature stages. The formation of the river extends along weak strata or cleavage planes, where the tributaries intersect the main river almost perpendicularly. The drainage system has a pattern in between dendritic and rectangular water network.

The construction of Chihpen River CDs results in the sediment deposition and the elevation of the riverbed. Continuous elevation may be disastrous to inhabitants residing downriver or on either side of the river. Therefore, lowering the height of the existent CDs should facilitate the discharge of excessive sediments. On the other hand, since the demolition of dam may increase the slope of the riverbed, which could lead to massive runoffs 


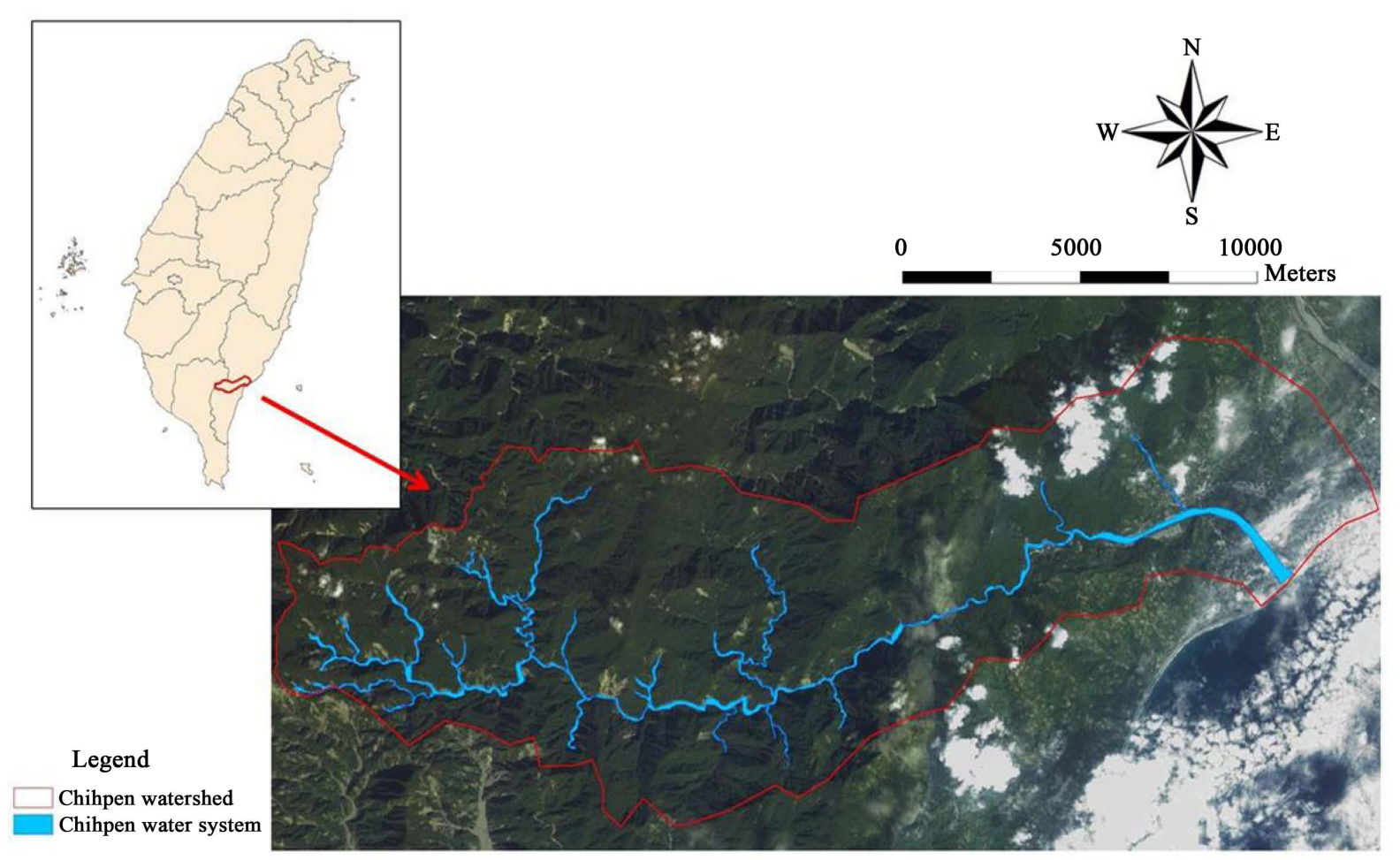

Figure 1. The location of study area.

with upriver sediments during typhoons or heavy rains, it is suggested that a regulative CD should be constructed upstream.

The selected site of the dam in this research is illustrated in Figure 2. Since the extant CDs primarily function as "sediments control", conventionally they are constructed at narrow sections of the river or mountain passes. On contrary, the purpose of the regulative CD, which will be demonstrated in this study, is "sediment regulation" instead of sediment trapping. Therefore, we chose the site for our research.

\subsection{Peak Folw Analysis}

The dam construction site which is roughly $600 \mathrm{~m}$ from Chihpen National Forest Recreational Area and Lelin Bridge was selected for simulation. It is roughly in the mid-river to downstream section of the Chihpen River. ArcGIS was used to determine the length, elevation difference, and the area of the river. The Rziha equation was employed to derive a $1.51 \mathrm{hr}$ concentration time at the simulated dam location, and to further deduce the peak flow of the river (Table 1 ).

In this study, the largest daily rainfall in each year from 1998 to 2015 was used to simulate various recurrence intervals at the simulated dam location. A Pearson's Type III regression model was applied to analyze data generated by the designed triangular unit hydrographs. The flow results at are shown in Table 2 . We first set the flow rate of various CD types at 50-year and 100-year recurrence intervals, and then performed hydraulic channel (HC) simulations to determine the influences on the dam caused by river sediments and the river sedimentation conditions. The flow calculations in this section are based on the results of the HC tests.

\subsection{Hydraulic Model Experiment}

\section{Test Channel}

An overview of the hydraulic test channel is illustrated in Figure 3. A top view and a side view of the channel are shown in Figure 4. The length and width of the test channel are $190 \mathrm{~cm}$ and $30 \mathrm{~cm}$, respectively. The crosssection of the dam location is $72 \mathrm{~m}$, while the width of the test channel is $30 \mathrm{~cm}$. Therefore, the cross-section of the dam location and the width of the test channel were converted to a ratio of 1:240, which is used for paving sediments collected from the research site in the channel and setting the flow at various recurrence intervals. 


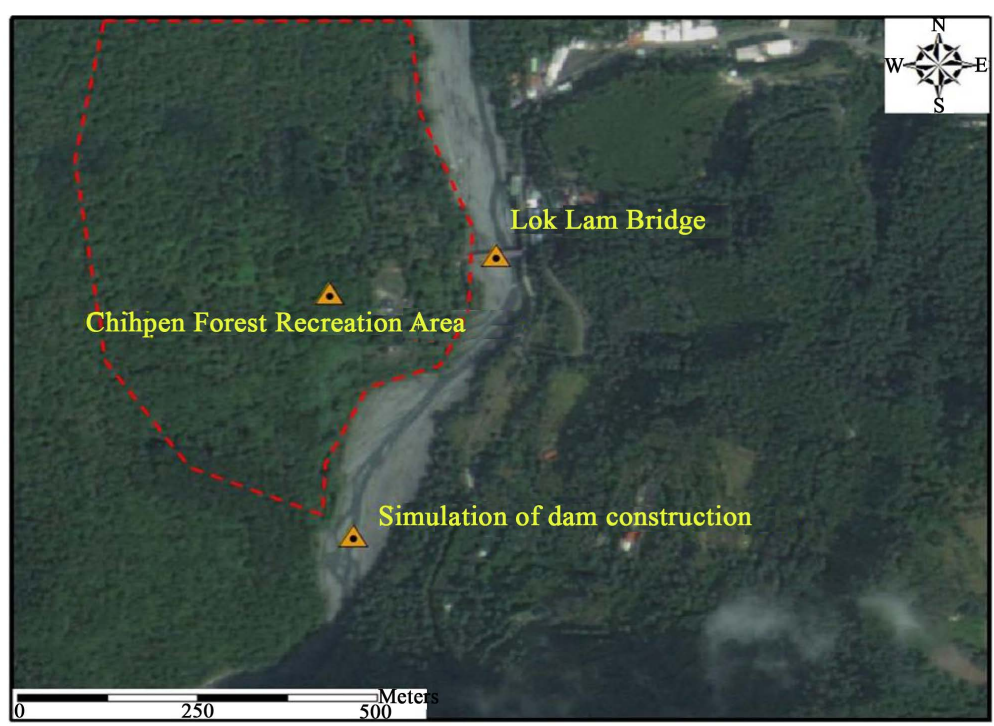

Figure 2. The selected dam location.

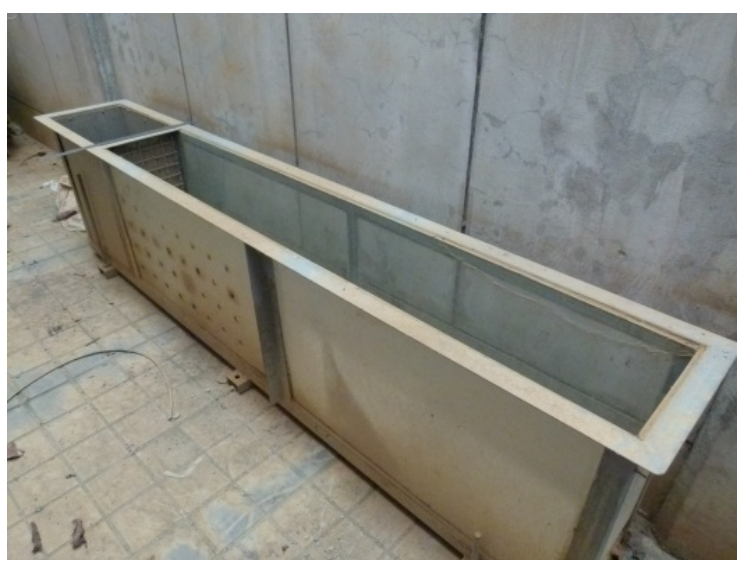

Figure 3. Photo of hydraulic model experiment channel.

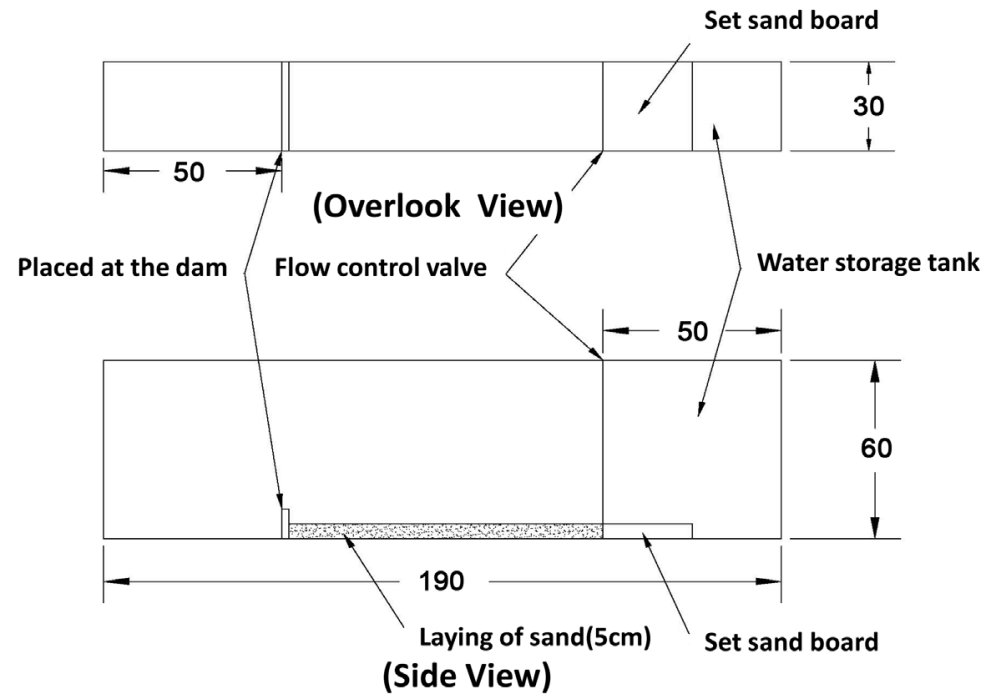

Figure 4. Overlook of hydraulic model experiment channel. 
Table 1. The parameters of peak flow simulated.

\begin{tabular}{ccccc}
\hline Area $(\mathbf{k m})$ & River length $(\mathbf{m})$ & Elevation difference $(\mathbf{m})$ & Overland flow length $(\mathbf{m})$ & Overland flow speed $(\mathbf{m} / \mathbf{s})$ \\
\hline 143.8 & 18.97 & 1318 & 300 & 0.4 \\
T1 (hr) & Flow rate (m/s) & T2 (hr) & Concentration time (hr) \\
0.208 & 4.037 & 1.305 & 1.51 \\
\hline
\end{tabular}

Table 2. Recurrence interval flow results.

\begin{tabular}{cccccccc}
\hline Recurrence interval & $\mathbf{2}$ & $\mathbf{5}$ & $\mathbf{1 0}$ & $\mathbf{2 5}$ & $\mathbf{5 0}$ & $\mathbf{1 0 0}$ & $\mathbf{2 0 0}$ \\
\hline Flow (cms) & 1528.0 & 2037.2 & 2296.7 & 2568.4 & 2741.1 & 2894.4 & 3033.3 \\
\hline
\end{tabular}

A valve was installed at the rear end of the $\mathrm{HC}$ and connected to a water tank. Once the water pressure was stabilized, the valve was used to control the flow of water and sediments were carried by the flow of water. When a constant flow was reached, a fixed amount of sediments was placed in the water tank. By using the gravity and water force to move the sediments, the amount of sediments transported during peak flow was measured to determine the ST effects of various types of CDs during 50-year and 100-year floods.

Four types of CDs (closed CD, SD, SPSD and SPD) were placed in the HC for simulations. Subsequently, a 5-cm layer of sediments was paved in the channel according to the down-scaling ratio to examine the ST effects of the various CDs and the sedimentation changes in the channel during flood peaks.

2. Types of Check Dams

The HC is smaller than the original river. Thus, the cross-section structures must be scaled to size. For testing, acrylic slabs were cut into the shapes of various dam types and used as the cross-sectional structures for simulations. Stainless steel meshes with a grid size of $2.5 \mathrm{~mm}$ were selected as the steel pipe material used in SPDs. At a scale of 1:240, a grid size of $2.5 \mathrm{~mm}$ would be converted to a grid size of $60 \mathrm{~cm}$ in the on-site SPD. Therefore, a stainless steel mesh with a porosity of $2.5 \mathrm{~mm}$ was used to simulate the ST effects of the simulated SPSD plus SPD.

The ST effects of four CDs (closed CD, SD, SPSD and SPDs) were simulated using 50-year and 100-year river discharge (Figure 5).

3. Design Experimental Sediment Particle Ratio

The width of the HC was $1 / 240$ of that of the riverbed. To realistically simulate sedimentation conditions, the particle size of the sediments measured in a field survey were reduced to 1/240 of the original size. The distribution curve is illustrated in Figure 6. To comply with actual conditions, the simulations must reflect the sediment particle distribution of the original riverbed. Figure 6 shows that the original median partial sizes were $149 \mathrm{~mm}$ (D50) and $250 \mathrm{~mm}$ (D95). A reduction to scale produced particle sizes of $0.62 \mathrm{~mm}$ for D50 and $1.04 \mathrm{~mm}$ for D95. Standard quartz sand was adopted as the experiment sediments. A proportionate amount of the sand was paved within the test channel and the water and sediment tanks. These sediments reflected the upriver sediments of the Chihpen River and it was used to observe the sedimentation conditions of the test channel.

\section{Results and Discussion}

\subsection{Sedimentation Results of the River Curse}

The experiment channel was around $190 \mathrm{~cm}$ in length. Anchors were placed on both side of the dam structure $(1$ $\mathrm{m}$ upriver and $0.4 \mathrm{~m}$ downriver) and then one every $10 \mathrm{~cm}$ apart. These anchors were used to measure the sedimentation changes of the riverbed using different transverse structures (closed CD, SD, SPSD and SPD) and river discharges (50-year and 100-year recurrence intervals).

The cross-sectional data of the riverbed are tabulated in Table 3. The table shows that sediments were transported by the river, where an increasing flow enabled the river to carry a greater amount of sediments downriver. According to the closed CD simulation results, the sediment volume measured on the riverbed in a recurrence interval of 50 years was significantly greater than that of a 100-year

A comparison between the closed CD, SD, SPSD and SPD structures showed that without the accumulation of sediments, the capacity of the closed CD was ample to trap and store the sediments. Channel tests were con- 
Table 3. Cross-sectional data of the hydraulic model experiment channel.

\begin{tabular}{|c|c|c|c|c|c|c|c|c|c|c|c|c|c|c|c|c|c|c|c|c|c|c|c|c|c|}
\hline \multirow{2}{*}{ Types } & \multirow{2}{*}{$\begin{array}{c}\text { Flow } \\
\text { (year) }\end{array}$} & \multicolumn{3}{|c|}{$\begin{array}{c}\text { Dam } \\
\text { upstream }\end{array}$} & \multicolumn{3}{|c|}{$\begin{array}{c}\text { Dam } \\
\text { downstream }\end{array}$} & \multicolumn{3}{|c|}{+10} & \multicolumn{3}{|c|}{+20} & \multicolumn{3}{|c|}{+30} & \multicolumn{3}{|c|}{+40} & \multicolumn{3}{|c|}{+50} & \multicolumn{3}{|c|}{+60} \\
\hline & & $\mathbf{L}$ & $\mathbf{M}$ & $\mathbf{R}$ & $\mathbf{L}$ & $\mathbf{M}$ & $\mathbf{R}$ & $\mathbf{L}$ & $\mathbf{M}$ & $\mathbf{R}$ & $\mathbf{L}$ & $\mathbf{M}$ & $\mathbf{R}$ & $\mathbf{L}$ & $\mathbf{M}$ & $\mathbf{R}$ & $\mathbf{L}$ & $\mathbf{M}$ & $\mathbf{R}$ & $\mathbf{L}$ & $\mathbf{M}$ & $\mathbf{R}$ & $\mathbf{L}$ & $\mathbf{M}$ & $\mathbf{R}$ \\
\hline CD & & 5.7 & 8.4 & 6.2 & - & - & - & 7.8 & 8.0 & 7.8 & 7.8 & 7.6 & 7.9 & 7.3 & 6.6 & 7.1 & 5.6 & 6.1 & 6.0 & 5.6 & 6.1 & 5.9 & 6.0 & 6.4 & 6.0 \\
\hline CD & 100 & 4.6 & 7.5 & 5.1 & - & - & - & 6.7 & 7.3 & 6.8 & 6.8 & 6.7 & 7.1 & 4.9 & 5.5 & 6.5 & 4.4 & 5.0 & 4.8 & 4.4 & 4.6 & 4.1 & 5.0 & 5.5 & 5.4 \\
\hline SD & 50 & 5.2 & 5.2 & 5.4 & - & - & - & 4.8 & 5.3 & 5.3 & 5.0 & 5.5 & 5.5 & 5.0 & 5.9 & 5.2 & 5.4 & 5.9 & 5.1 & 5.3 & 5.3 & 5.2 & 5.5 & 5.6 & 5.3 \\
\hline SD & 100 & 4.5 & 4.6 & 4.8 & 0.1 & 0.3 & 0.1 & 4.5 & 4.9 & 4.7 & 4.6 & 5.0 & 4.8 & 4.7 & 5.3 & 4.9 & 4.6 & 5.3 & 4.7 & 4.7 & 4.9 & 4.6 & 4.8 & 4.6 & 4.4 \\
\hline SPSD & 50 & 6.5 & 8.4 & 7.2 & - & - & - & 7.5 & 7.8 & 8.2 & 6.5 & 7.3 & 7.3 & 6.5 & 6.9 & 6.7 & 6.3 & 6.2 & 6.2 & 6.6 & 7.0 & 6.5 & 5.9 & 6.1 & 5.9 \\
\hline $\begin{array}{c}\text { SPSD } \\
\text { (remove) }\end{array}$ & 50 & 5.7 & 5.1 & 5.8 & 0.3 & 0.5 & 0.3 & 6.0 & 5.9 & 5.9 & 6.0 & 5.9 & 6.0 & 5.7 & 5.9 & 5.8 & 5.7 & 5.9 & 5.8 & 5.9 & 5.9 & 5.9 & 4.8 & 5.6 & 5.2 \\
\hline SPSD & 100 & 5.7 & 7.2 & 6.5 & - & - & - & 7.0 & 7.0 & 7.4 & 6.2 & 6.5 & 7.2 & 6.2 & 6.2 & 6.1 & 5.9 & 6.1 & 5.9 & 6.1 & 6.1 & 6.4 & 5.8 & 5.6 & 5.5 \\
\hline $\begin{array}{c}\text { SPSD } \\
\text { (remove) }\end{array}$ & & 4.2 & 5.8 & 5.4 & - & 0.1 & 0.2 & 5.5 & 5.7 & 5.8 & 5.9 & 5.9 & 5.7 & 5.4 & 5.8 & 5.8 & 5.7 & 5.8 & 5.5 & 5.8 & 5.9 & 5.8 & 4.5 & 5.4 & 5.0 \\
\hline SPD & 5 & 5.8 & 7.4 & 7.1 & - & - & - & 6.8 & 6.7 & 7.2 & 6.1 & 6.1 & 6.6 & 6.0 & 6.1 & 6.0 & 5.9 & 6.0 & 5.8 & 6.1 & 6.0 & 6.0 & 5.7 & 5.6 & 5.4 \\
\hline $\begin{array}{c}\text { SPD } \\
\text { (remove) }\end{array}$ & & 5.7 & 5.9 & 5.5 & 0.2 & - & 0.2 & 5.5 & 5.7 & 5.8 & 5.8 & 5.8 & 5.4 & 5.1 & 5.7 & 5.7 & 5.6 & 5.4 & 5.5 & 5.8 & 5.8 & 5.7 & 3.6 & 4.0 & 4.3 \\
\hline SPD & 100 & 5.2 & 7.1 & 6.4 & - & - & - & 6.6 & 6.6 & 6.6 & 6.0 & 6.1 & 6.0 & 6.0 & 6.0 & 5.9 & 5.7 & 5.9 & 5.8 & 5.9 & 6.0 & 5.9 & 5.2 & 5.6 & 5.3 \\
\hline $\begin{array}{c}\text { SPD } \\
\text { (remove) }\end{array}$ & 100 & 4.6 & 4.8 & 4.8 & - & - & - & 5.1 & 5.5 & 5.4 & 5.4 & 5.7 & 5.3 & 5.0 & 5.4 & 5.4 & 4.4 & 4.9 & 5.2 & 5.7 & 5.8 & 5.4 & 2.1 & 1.5 & 1.9 \\
\hline \multirow{2}{*}{ Types } & \multirow{2}{*}{$\begin{array}{l}\text { Flow } \\
\text { (year) }\end{array}$} & \multicolumn{3}{|c|}{+70} & \multicolumn{3}{|c|}{+80} & \multicolumn{3}{|c|}{+90} & \multicolumn{3}{|c|}{+100} & \multicolumn{3}{|c|}{-10} & \multicolumn{3}{|c|}{-20} & \multicolumn{3}{|c|}{-30} & \multicolumn{3}{|c|}{-40} \\
\hline & & $\mathrm{L}$ & M & $\mathrm{R}$ & L & M & $\mathrm{R}$ & $\mathrm{L}$ & M & $\mathrm{R}$ & $\mathrm{L}$ & $\mathrm{M}$ & $\mathrm{R}$ & $\mathrm{L}$ & $\mathrm{M}$ & $\mathrm{R}$ & $\mathrm{L}$ & $\mathrm{M}$ & $\mathrm{R}$ & $\mathrm{L}$ & $\mathrm{M}$ & $\mathrm{R}$ & $\mathrm{L}$ & M & $\mathrm{R}$ \\
\hline CD & 5 & 2.6 & 2.6 & 2.5 & 0.1 & 0.1 & 0.4 & 1.6 & 3.0 & 3.2 & 3.8 & 4.8 & 4.0 & - & - & - & - & - & 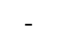 & & - & - & - & - & - \\
\hline CD & 100 & 1.0 & 1.3 & 1.8 & 0.1 & - & 0.1 & 0.7 & 1.5 & 1.9 & 3.0 & 4.2 & 3.7 & 0.2 & 0.7 & 0.7 & 0.3 & 0.3 & 0.3 & 0.2 & 0.3 & 0.3 & 0.2 & - & 0.1 \\
\hline SD & 50 & 1.5 & 1.6 & 2.1 & 0.1 & 0.1 & 0.1 & 1.0 & 2.1 & 2.3 & 3.6 & 4.8 & 4.0 & - & - & - & - & - & - & - & - & - & - & - & - \\
\hline SD & 100 & - & - & - & - & - & - & 0.6 & 1.1 & 1.8 & 2.0 & 3.8 & 3.7 & - & 0.1 & 0.2 & 0.1 & 0.2 & 0.1 & - & 0.2 & 0.1 & 0.1 & 0.1 & 0.1 \\
\hline SPSD & 50 & 1.6 & 1.7 & 2.2 & - & 0.1 & 0.2 & 1.0 & 1.8 & 2.2 & 3.2 & 4.7 & 3.9 & 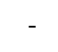 & - & - & - & 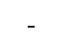 & - & - & - & - & - & - & - \\
\hline $\begin{array}{c}\text { SPSD } \\
\text { (remove) }\end{array}$ & 50 & 0.1 & - & 0.1 & - & - & - & 0.5 & 1.0 & 1.7 & 1.8 & 3.7 & 3.5 & 0.1 & - & 0.2 & 0.2 & 0.0 & 0.2 & 0.2 & - & 0.1 & 0.0 & 0.1 & 0.1 \\
\hline SPSD & 100 & 1.3 & 1.4 & 1.6 & - & - & 0.1 & 1.0 & 1.7 & 2.0 & 3.1 & 4.5 & 3.7 & - & - & - & - & - & - & - & - & - & - & - & - \\
\hline $\begin{array}{c}\text { SPSD } \\
\text { (remove) }\end{array}$ & 100 & - & - & 0.1 & - & - & - & 0.3 & 0.7 & 1.5 & 1.8 & 2.8 & 2.7 & - & - & - & - & - & - & - & - & - & - & - & - \\
\hline SPD & 50 & 2.6 & 2.6 & 2.5 & 0.1 & 0.1 & 0.4 & 1.6 & 3.0 & 3.2 & 3.8 & 4.8 & 4.0 & - & - & - & - & - & - & - & - & - & - & - & - \\
\hline $\begin{array}{c}\text { SPD } \\
\text { (remove) }\end{array}$ & 50 & 1.0 & 1.3 & 1.8 & 0.1 & - & 0.1 & 0.7 & 1.5 & 1.9 & 3.0 & 4.2 & 3.7 & 0.2 & 0.7 & 0.7 & 0.3 & 0.3 & 0.3 & 0.2 & 0.3 & 0.3 & 0.2 & - & 0.1 \\
\hline SPD & 100 & 1.5 & 1.6 & 2.1 & 0.1 & 0.1 & 0.1 & 1.0 & 2.1 & 2.3 & 3.6 & 4.8 & 4.0 & - & - & - & - & - & - & - & - & - & - & - & - \\
\hline $\begin{array}{c}\text { SPD } \\
\text { (remove) }\end{array}$ & 100 & - & - & - & - & - & - & 0.6 & 1.1 & 1.8 & 2.0 & 3.8 & 3.7 & - & 0.1 & 0.2 & 0.1 & 0.2 & 0.1 & - & 0.2 & 0.1 & 0.1 & 0.1 & 0.1 \\
\hline
\end{tabular}

NOTE. L: Left, R: Right, M: Mid, Unit: cm.

ducted with empty dam. The cross-sectional data in Table 3 shows that the ST effects of the closed CD were better than open CD. Since SDs are mostly used for landslide prevention worldwide, the ST effects of the SD structure were unfavorable because the particle size of sediments is smaller than the openings of SDs, so that the gaps between SDs cannot be filled up, which greatly reduces the ST effects of SDs.

In terms of the application of steel pipes, the increase of sediments accumulated in the SPD was significantly lower than that of the SPSD. SPDs use the grid structure formed by the metal pipes to trap large sentiments. 


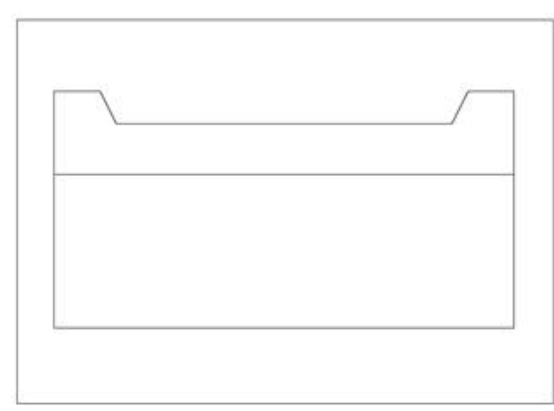

(a)

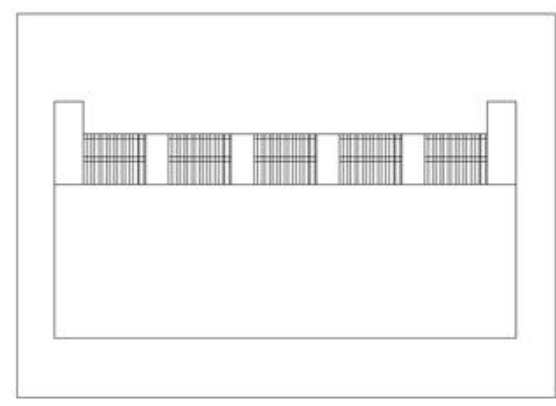

(c)

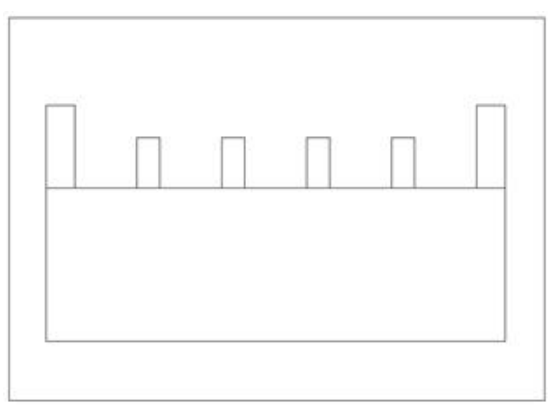

(b)

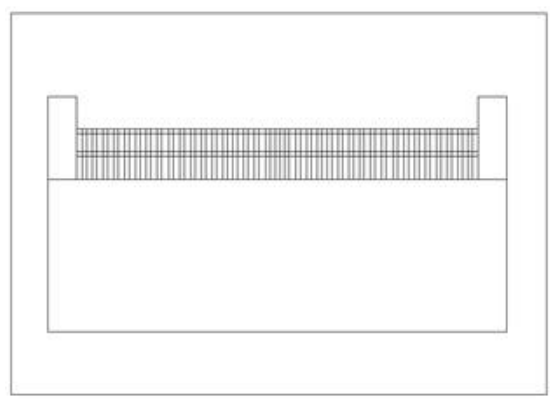

(d)

Figure 5. Types of Check Dams in this study. (a) CD; (b) SD; (c) SPSD; (d) SPD.

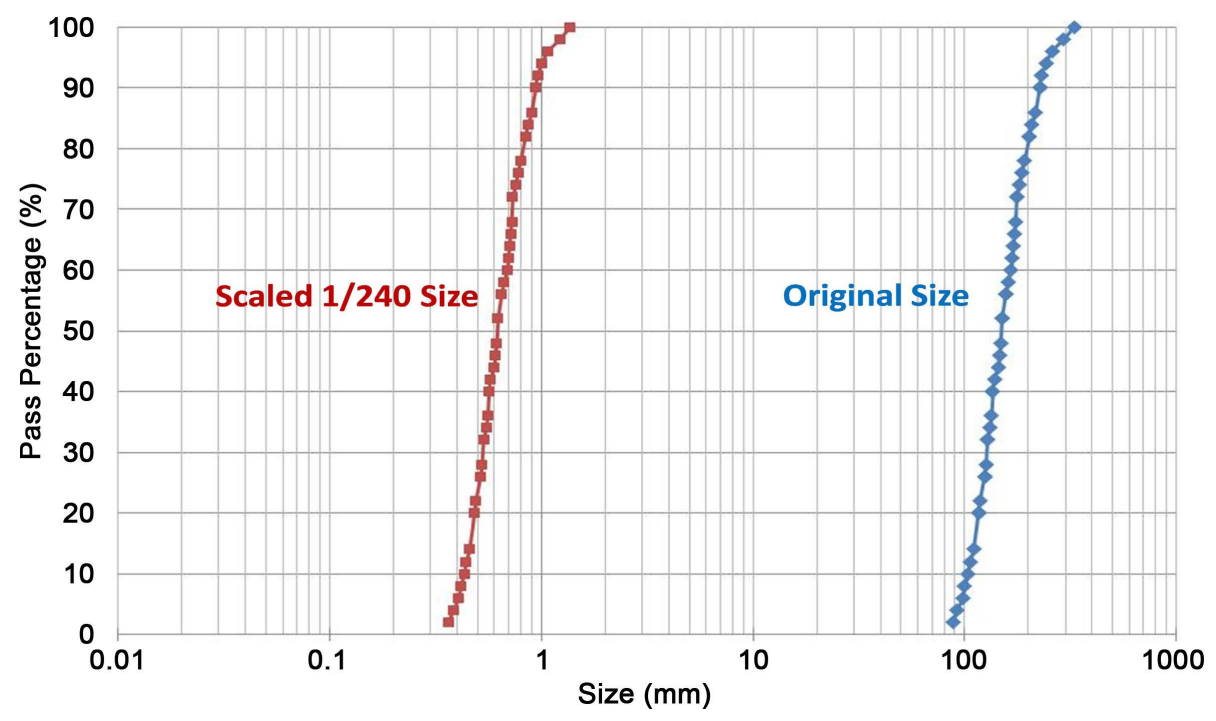

Figure 6. Original size distribution curve scaling of 1/240.

However, SPSDs can trap even more sediments because they protrude out of the river surface. The cross-sectional data of the SPD and SPSD structures in Table 3 show that both of them can trap sediments before the disassembly of the dam components. After the disassembly, the height of the dam structure is lowered, that effectively allows sediments to flow downriver, thereby achieving the function of sedimentation regulation of the riverbed.

Fixed widths of Stainless steel meshes were used to simulate the SPDs because they are easy to disassemble. The SPDs can effectively hold larger amount of sediments on the upriver side of the dam, reducing the potential crises downstream caused by flood peaks. After a flood episode, SPDs can be disassembled for releasing the trapping capacity and allowing the excessive sediments to flow down the river, thereby fully utilizing the advantages of regulative CDs. Hopefully this concept can be applied to the river dam engineering in the future. 


\subsection{Sediment Trapping in Different Transverse Structures}

Each kind of transverse structures were put in the test channel to simulate sediment retention under conditions of 50-year and 100-year recurrence interval. Each group underwent three test cycles. $5 \mathrm{~kg}$ of quartz sand was placed in the test channel for each test. The outflow of sand was collected, filtered and analyzed to determine the relationship between ST effects and change in sedimentary particle size in various CDs. The amount and ratio of different size of particle in the outflow of each dam are shown in Table 4 and Table 5.

According to Table 4, the outflow quantity of the closed CD was significantly less than the other transverse structures because a greater trapping ability reduces the amount of sediment outflow. The closed CD demonstrated a better ST effect, followed by the SPSD. Since the SD is a form of open CD and its trapping area decreases concurrently with the increase in opening size, the ST effects of the SD were significantly lower than the closed CD. On the other hand, the outflow quantity of the SPSD decreases accordingly with an increase in trapping area. Although the SPD is also a type of open dam, its opening is relatively small than a SD (Table 4). Thus, the ST effect of the SPD was more favorable than that of the SD.

Table 4. Different particle amount in the outflow of each type dam.

\begin{tabular}{|c|c|c|c|c|c|c|c|c|c|c|c|c|}
\hline \multirow{2}{*}{ Mesh } & \multicolumn{2}{|c|}{ CD } & \multicolumn{2}{|c|}{ SD } & \multicolumn{4}{|c|}{ SPSD } & \multicolumn{4}{|c|}{ SPD } \\
\hline & 50 & 100 & 50 & 100 & 50 & Remove & 100 & Remove & 50 & Remove & 100 & Remove \\
\hline 4 & 0 & 0 & 0 & 0 & 0 & 0 & 0 & 0 & 0 & 0 & 0 & 0 \\
\hline 8 & 65 & 133 & 220 & 245 & 105 & 270 & 130 & 288 & 143 & 350 & 139 & 484 \\
\hline 16 & 1154 & 1426 & 1664 & 1873 & 1237 & 2190 & 1444 & 3006 & 1356 & 2449 & 1548 & 3425 \\
\hline 30 & 1073 & 1394 & 1567 & 1738 & 1346 & 1516 & 1469 & 2030 & 1466 & 1775 & 1638 & 1900 \\
\hline 50 & 782 & 947 & 1104 & 1225 & 1221 & 946 & 1240 & 1072 & 1448 & 959 & 1609 & 1068 \\
\hline 100 & 13 & 16 & 17 & 19 & 13 & 22 & 13 & 16 & 13 & 9 & 17 & 20 \\
\hline 200 & 0 & 0 & 0 & 0 & 0 & 0 & 0 & 0 & 0 & 3 & 0 & 0 \\
\hline Chassis & 3 & 4 & 3 & 4 & 4 & 4 & 5 & 4 & 4 & 2 & 6 & 4 \\
\hline Total & 3089 & 3920 & 4573 & 5103 & 3926 & 4948 & 4301 & 6416 & 4430 & 5547 & 4957 & 6901 \\
\hline
\end{tabular}

Unit: g.

Table 5. Different particle ratio in the outflow of each type dam.

\begin{tabular}{|c|c|c|c|c|c|c|c|c|c|c|c|c|}
\hline \multirow{2}{*}{ Mesh } & \multicolumn{2}{|c|}{ CD } & \multicolumn{2}{|c|}{ SD } & \multicolumn{4}{|c|}{ SPSD } & \multicolumn{4}{|c|}{ SPD } \\
\hline & 50 & 100 & 50 & 100 & 50 & Remove & 100 & Remove & 50 & Remove & 100 & Remove \\
\hline 4 & 0.00 & 0.00 & 0.00 & 0.00 & 0.00 & 0.00 & 0.00 & 0.00 & 0.00 & 0.00 & 0.00 & 0.00 \\
\hline 8 & 2.09 & 3.40 & 4.80 & 4.79 & 2.67 & 5.46 & 3.02 & 4.49 & 3.22 & 6.31 & 2.80 & 7.01 \\
\hline 16 & 37.35 & 36.37 & 36.38 & 36.70 & 31.51 & 44.26 & 33.58 & 46.85 & 30.61 & 44.15 & 31.23 & 49.63 \\
\hline 30 & 34.72 & 35.56 & 34.26 & 34.06 & 34.28 & 30.64 & 34.16 & 31.64 & 33.10 & 32.00 & 33.05 & 27.53 \\
\hline 50 & 25.31 & 24.15 & 24.13 & 24.00 & 31.11 & 19.12 & 28.84 & 16.71 & 32.68 & 17.29 & 32.45 & 15.48 \\
\hline 100 & 0.41 & 0.41 & 0.36 & 0.38 & 0.33 & 0.44 & 0.30 & 0.25 & 0.30 & 0.16 & 0.35 & 0.29 \\
\hline 200 & 0.00 & 0.00 & 0.00 & 0.00 & 0.00 & 0.00 & 0.00 & 0.00 & 0.00 & 0.05 & 0.00 & 0.00 \\
\hline Chassis & 0.11 & 0.11 & 0.07 & 0.07 & 0.10 & 0.08 & 0.11 & 0.06 & 0.09 & 0.04 & 0.12 & 0.06 \\
\hline Total & 100 & 100 & 100 & 100 & 100 & 100 & 100 & 100 & 100 & 100 & 0.00 & 100 \\
\hline
\end{tabular}

Unit: \%. 
One of the advantages of SPDs is that it can be disassembled rapidly and conveniently. In this study a stainless steel mesh was used to simulate steel pipes. The stainless steel mesh was removed after the channel test was performed on the transverse structure for measuring the outflow quantity and the change in sediment particle size. As shown in Table 4, the ST effects of dam using steel pipes were less favorable than conventional closed CDs. However, the combination of SDs and steel pipes (SPSD) significantly improved the ST effects of SDs. The benefit of stainless steel mesh utilization is that it is "regulative": not only traps excessive sediments but also prevents potential downstream disasters. Comparatively, the ultimate goal for CDs is to maintain their capacity rather than trapping more sediment. Continuous trapping of sediments may lead to the rise of riverbed and the reduction of the flood channeling cross section, which increase the chances of flooding, endangering the side slopes and residents by the river.

The size distribution of sediments in the discharge from various transverse structures is listed in Table 5. In closed CD and SD, when stainless steel mesh was not used, the size distribution patterns in simulation model and field site were almost proportionally identical. When steel pipes (stainless steel mesh in the simulation) were incorporated, the sediment size ratios changed significantly. The space between the steel pipes influences the size of the sediments retained upriver. Thus, the retention ratio at Filter No. 16 (1.18 mm) reduced significantly, while the retention ratio at Filter No. $50(0.3 \mathrm{~mm})$ increased significantly. These results show that the use of steel pipes in dam changes the particle size ratio of the sediments, effectively traps larger sediments upriver.

The size ratio of the sediments also changed drastically after the removal of the stainless steel mesh. As seen in Table 5, the size ratio of the outflow sediment significantly increased once the stainless steel mesh was removed from the dam, particularly Filters No. 8 and No. 16. These results indicate that a decrease in spacing between the metal pipes suppresses larger sediments from moving downriver. When a flood peak arrives, these dams can effectively trap large sediments from traveling downriver, reducing their impact and the occurrence of a disaster.

\section{Conclusion and Suggestions}

\subsection{Conclusions}

1) Sediments are transported by floodwater. The larger the discharge is, the more sediment is transported downriver. According to the closed CD simulation results, the sediment volume measured on the riverbed in a recurrence interval of a 50-year was significantly greater than that of a 100 -year.

2) The sediment outflow of closed CDs was significantly less than the other transverse structures, suggesting that closed CDs could trap more sediment and manifested a more favorable ST effect, followed by the SPSD. Since the SD is a form of open CD and its trapping area decreases concurrently with the increase in opening size, the ST effects of the SD were significantly lower than the closed CD. On the other hand, the outflow quantity of the SPSD decreases accordingly with an increase in trapping area. Although the SPD is also a type of open dam, its opening is relatively small than a SD (Table 4). Thus, the ST effect of the SPD was more favorable than that of the SD.

3) The combination of SDs and steel pipes (SPSD) significantly improved the ST effects of SDs. The benefit of stainless steel mesh utilization is that it is "regulative": not only traps excessive sediments but also prevents potential downstream disasters. Comparatively, the ultimate goal for CDs is to maintain their capacity rather than trapping more sediment. Continuous trapping of sediments may lead to the rise of riverbed and the reduction of the flood channeling cross section, which increase the chances of flooding, endangering the side slopes and residents by the river.

4) In closed CD and SD, when stainless steel mesh was not used, the size distribution patterns in simulation model and field site were almost proportionally identical. When steel pipes (stainless steel mesh in the simulation) were incorporated, the sediment size ratios changed significantly. The space between the steel pipes influences the size of the sediments retained upriver. Thus, the retention ratio at Filter No. 16 (1.18 mm) reduced significantly, while the retention ratio at Filter No. $50(0.3 \mathrm{~mm})$ increased significantly. These results show that the use of steel pipes in dam changes the particle size ratio of the sediments, effectively traps larger sediments upriver.

5) The size ratio of the sediments also changed drastically after the removal of the stainless steel mesh. The size ratio of the outflow sediment significantly increased once the stainless steel mesh was removed from the dam, particularly Filters No. 8 and No. 16. These results indicate that a decrease in spacing between the metal 
pipes suppresses larger sediments from moving downriver. When a flood peak arrives, these dams can effectively trap large sediments from traveling downriver, reducing their impact and the occurrence of a disaster.

\subsection{Suggestions}

1) Steel pipes can be disassembled easily and conveniently. The incorporation of steel pipes can enhance the ST performance of dam, retaining larger sediments upriver and thus reducing the damages when they flow downriver. After flood peaks, SPD can be disassembled to reduce ST, facilitating the transportation of sediments accumulated during the flood. In this manner, dam become regulative and adjustable. The concept can hopefully be applied in the future construction of river dam.

2) In this study we scaled the width of the Chihpen River proportionately to test the ST effects of various CDs. It is suggested that future research can focus on the micro-observations on the opening intervals of open CDs to determine the transportation pattern of sediments through dam openings and the changes in the riverbed upriver and downriver.

\section{References}

[1] Pan, J.J. and Huang, H.P. (1995) Study on Hydraulic Characteristic of Series of Sabo Dams. Journal of Taiwan Agricultural Engineers, 41, 38-46.

[2] Hsu, C.K., Lin, B.S., Hung, S.H., Chi, S.Y., Chiu, S.Y. and Chung, C.R. (2012) The Evaluation of Trapped Sediment and Deposition Gradients for the Check Dams in Shih-Men Reservoir Watershed. Journal of Soil and Water Technology, 7, 162-172.

[3] Lien, H.P. and Tsai, I.T. (2013) A Computational Model of Sediment Control for Soil and Water Conservation Engineering. Journal of Chinese Soil and Water Conservation, 44, 351-362.

[4] Chen, S.C., Chao, Y.C. and An, S.P. (2007) Fine Sediment Trapping Effect by Porous Check Dams. Journal of Chinese Soil and Water Conservation, 38, 55-63.

[5] Chen, S.C. and Wu, C.Y. (2014) Debris Flow Disaster Prevention and Mitigation of NonStructural Strategies in Taiwan. Journal of Mountain Science, 11, 308-322. http://dx.doi.org/10.1007/s11629-014-2987-3

[6] Poff, N.L. and Hart, D.D. (2002) How Dams Vary and Why It Matters for the Emerging Science of Dam Removal. Bioscience, 52, 659-668. http://dx.doi.org/10.1641/0006-3568(2002)052[0659:HDVAWI]2.0.CO;2

[7] Pizzuto, J. (2002) Effects of Dam Removal on River Form and Process. Bioscience, 52, 683-691. http://dx.doi.org/10.1641/0006-3568(2002)052[0683:EODROR]2.0.CO;2

[8] Doyle, M.W., Harbor, J.M. and Stanley, E.H. (2003) Toward Policies and Decision-Making for Dam Removal. Environmental Management, 31, 453-465. http://dx.doi.org/10.1007/s00267-002-2819-z

[9] Doyle, M.W., Stanley, E.H. and Harbor, J.M. (2003) Channel Adjustments Following Two Dam Removals in Wisconsin. Water Resources Research, 39, ESG2-1-2-15.

[10] Lorang, M.S. and Aggett, G. (2005) Potential Sedimentation Impacts Related to Dam Removal: Lcicle Creek, Washington, USA. Geomorphology, 71, 182-201. http://dx.doi.org/10.1016/j.geomorph.2004.10.013

[11] Ashley, J.T.F., Newton, K.B., Wilhelm, M., Boettner, A., Drames, G. and Velunsky, D.J. (2006) The Effects of Small Dam Removal on the Distribution of Sedimentary Contaminants. Environmental Monitoring and Assessment, 114 287-312.

[12] Armanini, A. and Larcher, M. (2001) Ration Criterion for Designing Opening of Slit-Check Dam. Journal of Hydraulic Engineering, 127, 94-104. http://dx.doi.org/10.1061/(ASCE)0733-9429(2001)127:2(94)

[13] Wang, C.Y., Yeh, C.H., Cheng, J.H., Duan, J.S. and Lu, C.L. (2010) Model Experiment on the Check Dam Removal: A Case Study of Chi-Chia-Wan Creek Dam NO. 1. Journal of Soil and Water Conversation, 42, 423-437.

[14] Hsu, C.L. and Chen, C.I. (2007) The Effects Evaluation of Watershed Sediment Control Stratagem in Taitung Ansowshi Watershed. Journal of Slopeland Hazard Prevention, 6, 45-58.

[15] Chen, S.-T., Shu, H.-M., Dai, S.-Y., Huang J.-M. and Hsu, C.-L. (2015) The Suitability of Typhoon Disaster Reconstruction Work Planning-A Case of Meizuolyu Stream in Taitung County. Engineering, 7, 237-247. http://dx.doi.org/10.4236/eng.2015.75021 


\section{Submit or recommend next manuscript to SCIRP and we will provide best service for you:}

Accepting pre-submission inquiries through Email, Facebook, LinkedIn, Twitter, etc.

A wide selection of journals (inclusive of 9 subjects, more than 200 journals)

Providing 24-hour high-quality service

User-friendly online submission system

Fair and swift peer-review system

Efficient typesetting and proofreading procedure

Display of the result of downloads and visits, as well as the number of cited articles

Maximum dissemination of your research work

Submit your manuscript at: http://papersubmission.scirp.org/ 